\title{
High-frequency atmospherically-induced oscillations in the middle Adriatic coastal area
}

\author{
I. Vilibić and G. Beg Paklar \\ Institute of Oceanography and Fisheries, Šetalište I. Meštrovića 63, 21000 Split, Croatia \\ Received: 7 March 2006 - Revised: 5 September 2006 - Accepted: 18 September 2006 - Published: 21 November 2006
}

\begin{abstract}
Temporal and spatial characteristics of the resonant coupling between travelling air pressure disturbances and the middle Adriatic coastal waters are examined using a barotropic numerical model for a one year period (July 2000-July 2001). The model is forced by the travelling air pressure disturbances reconstructed from the 2-min resolution air pressure series measured at Split. Six experiments for the studied period are performed, in order to analyse the influence of the speed and disturbance direction on the resonant coupling. The first group of three experiments uses variable disturbance direction, whereas in the second three, a constant direction is employed during the whole experiment. Disturbance direction for the first group of experiments is computed from the 500-mb geopotential data provided by European Center for Medium Range Weather Forecast (ECMWF), as it is found that all of the past extreme events are correlated with them. Each experiment, with variable and constant disturbance direction, is repeated with three different constant values of 10,20 and $30 \mathrm{~m} / \mathrm{s}$ for the disturbance speed. The model verification on the Split sea level data reveals that the model reproduces most of the events but also overestimates/underestimates some of them and creates some false events due to the rigid assumption of a constant disturbance speed. The best agreement with data is obtained in the model runs assuming a disturbance speed of $20 \mathrm{~m} / \mathrm{s}$. A number of trapped and edge waves have been modelled at the constrictions and along the coast, in particular on a shoal that lies off Split perpendicular to the channel axis. The importance of the disturbance direction to the energy content is highlighted, particularly close to the shore, where the difference may be significant at 2-3 times on average, up to $30 \mathrm{~cm}$ in maximum amplitude.
\end{abstract}

Keywords. Oceanography: general (Numerical modelling) - Oceanography: physical (Air-sea interactions; Tsunamis and storm surges)

Correspondence to: I. Vilibić

(vilibic@izor.hr)

\section{Introduction}

Although not as remarkable and devastating as tectonically generated tsunamis, barotropic ocean waves generated through resonant coupling with travelling atmospheric disturbances (Proudman, 1929; 1953), also called meteorological tsunamis or meteotsunamis (Defant, 1961; Rabinovich and Monserrat, 1998), may result in flooding and high damage in some bays and harbours by excitation of their normal bay modes (Hibiya and Kajiura, 1982; Monserrat et al., 1991a; Rabinovich, 1993; Goring, 2005). Another difference from the ordinary tsunami waves is that meteotsunami waves are frequently observed throughout a year (Vilibić and Mihanović, 2005), although the extreme flood events occur preferably in spring/summer (Garcies et al., 1996; Monserrat et al., 1998), presumably due to a more frequent occurrence of atmospheric gravity waves with appropriate propagating velocity and direction (Monserrat et al., 1991b; Vilibić et al., 2005). Resonant coupling of the travelling air pressure disturbances and sea or lake waters has been observed at various places around the world (a comprehensive list is given in Vilibić et al., 2004). Yet strong excitation of coastal seiches by the resonant open-ocean incoming waves is documented to occur at the Balearic Islands, Nagasaki Bay and coastal middle Adriatic waters (Vela Luka and Stari Grad Bays) only, although there are still some evidences submitted for several other places, too (e.g. Sicily - Candela et al., 1999; Malta Drago, 2004; Greece - Papadopoulos, 1993; New Zealand - Goring, 2005). Beyond the energy of atmospheric gravity waves and their propagation speed and direction large oscillations are favoured by the shape of a basin, preferably with both depth and width decreasing semi-uniformly towards the basin head.

While the source of the atmospheric gravity disturbances may be associated with a variety of atmospheric processes (e.g. atmospheric gravity waves, pressure jumps, frontal passages, squalls), the extreme events are probably a result of dynamical instability induced by wind shear in the lower atmosphere, as observed by a sounding over the Balearic Islands (Monserrat and Thorpe, 1992). However, the generated

Published by Copernicus GmbH on behalf of the European Geosciences Union. 


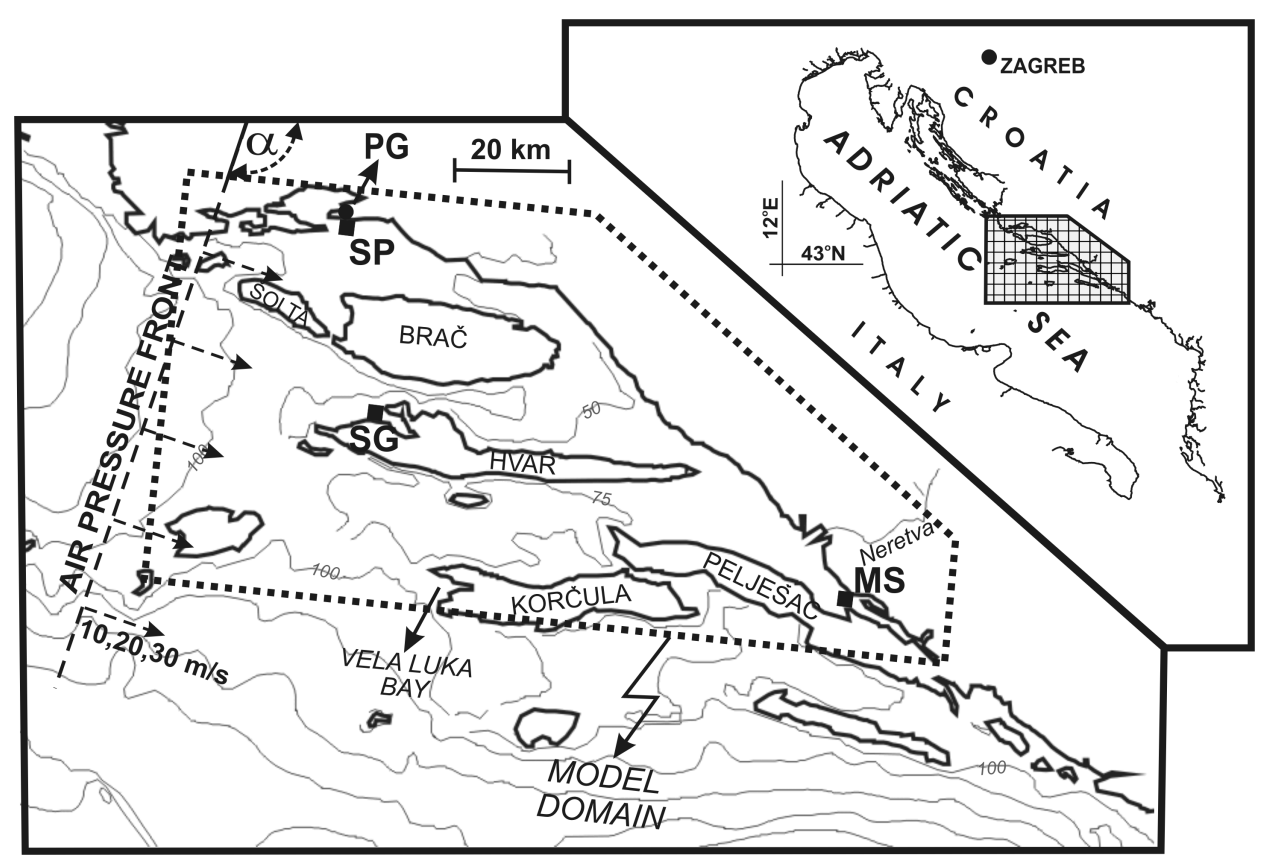

Fig. 1. Position and bathymetry of the eastern part of the middle Adriatic Sea. The domain of numerical model is dashed, with grid points (rectangles) marked in front of Split (SP), and Mali Ston (MS) and Stari Grad (SG) Bays. PG stands for the pressure gauge station at Split. Speed and direction $(\alpha)$ of the travelling air pressure disturbance are shown, too.

waves are not necessarily detected at the sea surface. They could be trapped in a stable lower troposphere (up to approximately $4 \mathrm{~km}$ ) with an unstable reflecting layer (Richardson number lower than 0.25, Lindzen and Tung, 1976) above. These conditions enable the non-dispersive characteristic of the waves visible on the surface air pressure series, allowing them to travel over a long distance without dissipating much of their energy (Monserrat and Thorpe, 1996). However, the proof for this "ducting theory" should be supplied by additional numerical studies rather than analytical theory. Another propagation mechanism seems to be the "self-feeding convective cell", which was recently reproduced by the MM5 mesoscale model (Belušić et al., 2006) for the 2003 Adriatic case. This means that a gravity perturbation, once it is generated and advected over the warm sea, is fed by the large influx of moisture on its front, resulting in a strong uplift in the whole troposphere. As the Adriatic Sea was heated quite anomalously in May/June 2003 (e.g. Orlić et al., 2006), resulting in a sea surface temperature of about $26-27^{\circ} \mathrm{C}$ in late June 2003, such conditions allowed for the self-feeding and growing of the gravity perturbation on its way along the Adriatic Sea.

The most extreme recent meteotsunami events in the middle Adriatic coastal waters were observed in June 1978 in Vela Luka Bay (Orlić, 1980) and June 2003 in Stari Grad and Mali Ston Bays (Vilibić et al., 2004), when severe damage was reported. The latter event was fairly well captured by a number of barographs and tide gauge stations, while the resonant nature of the process was verified by the nonlinear barotropic numerical model. Favourable conditions for extreme events include the shape of the air pressure travelling disturbance (Vilibić, 2005), whose energy content should be large in high-frequencies, in particular near normal mode frequencies of the affected bays (Rabinovich and Monserrat, 1998). Nevertheless, if the disturbance possesses significant energies at lower frequencies (periods above $1-2 \mathrm{~h}$ ), a large 4-h seiche (fundamental mode of the whole middle Adriatic coastal waters) could occur as strong as in August 2004 (Vilibić et al., 2005), but fortunately not coupled with the flood of hot spot areas.

This paper will not concentrate on the specific Adriatic meteotsunami events only; it will focuse on the steadiness in time and on the influence of the disturbance direction and speed to the sea level energy occurring in one year. A modelling approach will be used due to the lack of continuous high-frequency sea level data, assuming a constant speed of high-frequency atmospheric disturbances which affect the modelled area, whereas their direction will be the same as the wind direction at 500-mb level. Details and verification of this choice are discussed in Sect. 2. The model results described and discussed in Sects. 3 and 4 will give insight into the importance of the atmospheric disturbance speed and the direction of the spatial and temporal characteristics of the resonant coupling, distribution of the most affected areas and expected ocean energy content. Model results are compared with measured sea levels and discussed in the frame of the most extreme events. 


\section{Material and methods}

The eastern middle Adriatic Sea is a complex bay system open to the west with a number of along-bay islands and channels (Fig. 1). The depth decreases constantly from $100 \mathrm{~m}$ at the entrance to about $15 \mathrm{~m}$ in the inner part off Mali Ston Bay. The pressure gauge station at Split (PG, Fig. 1) will be used for the description of the atmospheric gravity waves detectable as high-frequency air pressure oscillations, as it collects air pressure data every $2 \mathrm{~min}$. The best data in terms of their quality were collected just after the installation in June 2000, so the pressure series used in the analysis will encompass the period from 1 July 2000 to 1 July 2001. After that, a number of weekly or even monthly gaps occurred, due to severe problems with the equipment functionality. Unfortunately, no other digital high-frequency stations were operational in the region at that time, thus disallowing the spatial analysis of the gravity disturbances (speed and direction). At the same time bottom pressure has been measured at the same station with a temporal resolution of $30 \mathrm{~s}$, enabling the computation of sea level height. These data will be used for verification of the model results.

The energy transfer from the atmosphere to the sea is reproduced by applying a version of 2-D numerical model (Black, 1995) with direct air pressure forcing only. Two group of experiments, simulating the entire July 2000-July 2001 interval with variable and constant disturbance direction $\alpha$, are performed. The model is based on the momentum equation containing an air pressure forcing term and continuity equation:

$$
\begin{aligned}
& \frac{\partial u}{\partial t}+u \frac{\partial u}{\partial x}+v \frac{\partial u}{\partial y}-f v= \\
& -g \frac{\partial \zeta}{\partial x}-\frac{g u\left(u^{2}+v^{2}\right)^{1 / 2}}{C^{2}(d+\zeta)}-\frac{1}{\rho} \frac{\partial P}{\partial x}+A_{H}\left(\frac{\partial^{2} u}{\partial x^{2}}+\frac{\partial^{2} u}{\partial y^{2}}\right)
\end{aligned}
$$

$$
\begin{aligned}
& \frac{\partial v}{\partial t}+u \frac{\partial v}{\partial x}+v \frac{\partial v}{\partial y}+f u= \\
& -g \frac{\partial \zeta}{\partial y}-\frac{g v\left(u^{2}+v^{2}\right)^{1 / 2}}{C^{2}(d+\zeta)}-\frac{1}{\rho} \frac{\partial P}{\partial y}+A_{H}\left(\frac{\partial^{2} v}{\partial x^{2}}+\frac{\partial^{2} v}{\partial y^{2}}\right) \\
& \frac{\partial \zeta}{\partial t}+\frac{\partial}{\partial x}[(d+\zeta) u]+\frac{\partial}{\partial y}[(d+\zeta) v]=0
\end{aligned}
$$

where $t$ is time, $u$ and $v$ are vertically averaged velocities in the $x$ and $y$ directions, $g$ is acceleration due to gravity $\left(9.81 \mathrm{~m} / \mathrm{s}^{2}\right), \zeta$ stands for the sea level above a horizontal datum, $d$ marks the water depth below the datum, $f$ is the Coriolis parameter, $\rho\left(1028 \mathrm{~kg} / \mathrm{m}^{3}\right)$ and $\rho_{a}$ are the water and air density, respectively, $P$ denotes air pressure and $A_{H}$ is the horizontal eddy viscosity coefficient. Seabed frictional resistance $C$ is given by

$C=18 \log _{10}\left(0.37 h / z_{0}\right)$,

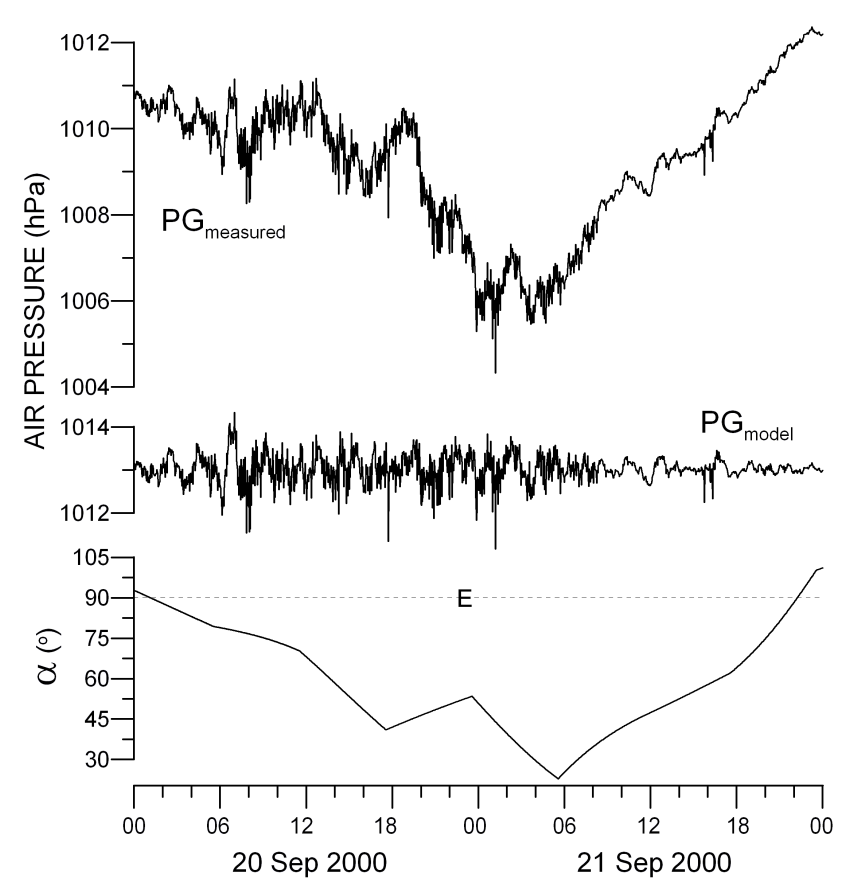

Fig. 2. Measured air pressure time series $\left(\mathrm{PG}_{\text {measured }}\right)$ and corresponding filtered values $\left(\mathrm{PG}_{\text {model }}\right)$ used by the model, together with the wind direction at 500-mb level used for the direction $(\alpha)$ of travelling pressure disturbances for 20 and 21 September 2000.

where $h$ is total water depth and $z_{0}$ is the roughness length (a level above the bed where velocity equals zero). An explicit leapfrog scheme is used to solve the Eqs. (1)-(4).

The model domain (Fig. 1) is originally developed for investigations of the tsunami event which occurred in the region (Herak et al., 2001), and has been used in previous case studies by Vilibić et al. (2004, 2005) and Vilibić (2005). Grid points corresponding to the locations of Split (SP) and two of the most vulnerable bays in the area Stari Grad (SG) and Mali Ston (MS) are denoted in Fig. 1, together with the location of the air pressure station (PG) whose data were used in the model runs and subsequent analysis. The chosen grid resolution is $1 \mathrm{~km}$ and the area is covered with $139 \times 68$ grid cells. Such a grid resolution is capable of capturing the impact of all possible air pressure disturbances included in the study, since their wavelengths are not smaller than $4.8 \mathrm{~km}$ (velocity of $20 \mathrm{~m} / \mathrm{s}$ multiplied by minimum 4-min disturbance period). The simulations were carried out with time steps of $12 \mathrm{~s}$, in order to satisfy the stability criterion for the grid sizes and depths considered. The horizontal eddy viscosity coefficient $A_{H}$ was set to $75 \mathrm{~m}^{2} / \mathrm{s}$, bottom roughness $z_{0}$ to $0.003 \mathrm{~m}$, while a radiation condition was imposed at the open boundaries.

The model has been forced by a travelling air pressure disturbance only, as the effect of the wind is minor even for relatively strong winds $(15 \mathrm{~m} / \mathrm{s}$ during 2004 case, see Vilibić et al., 2005). The disturbance has been introduced in the model 

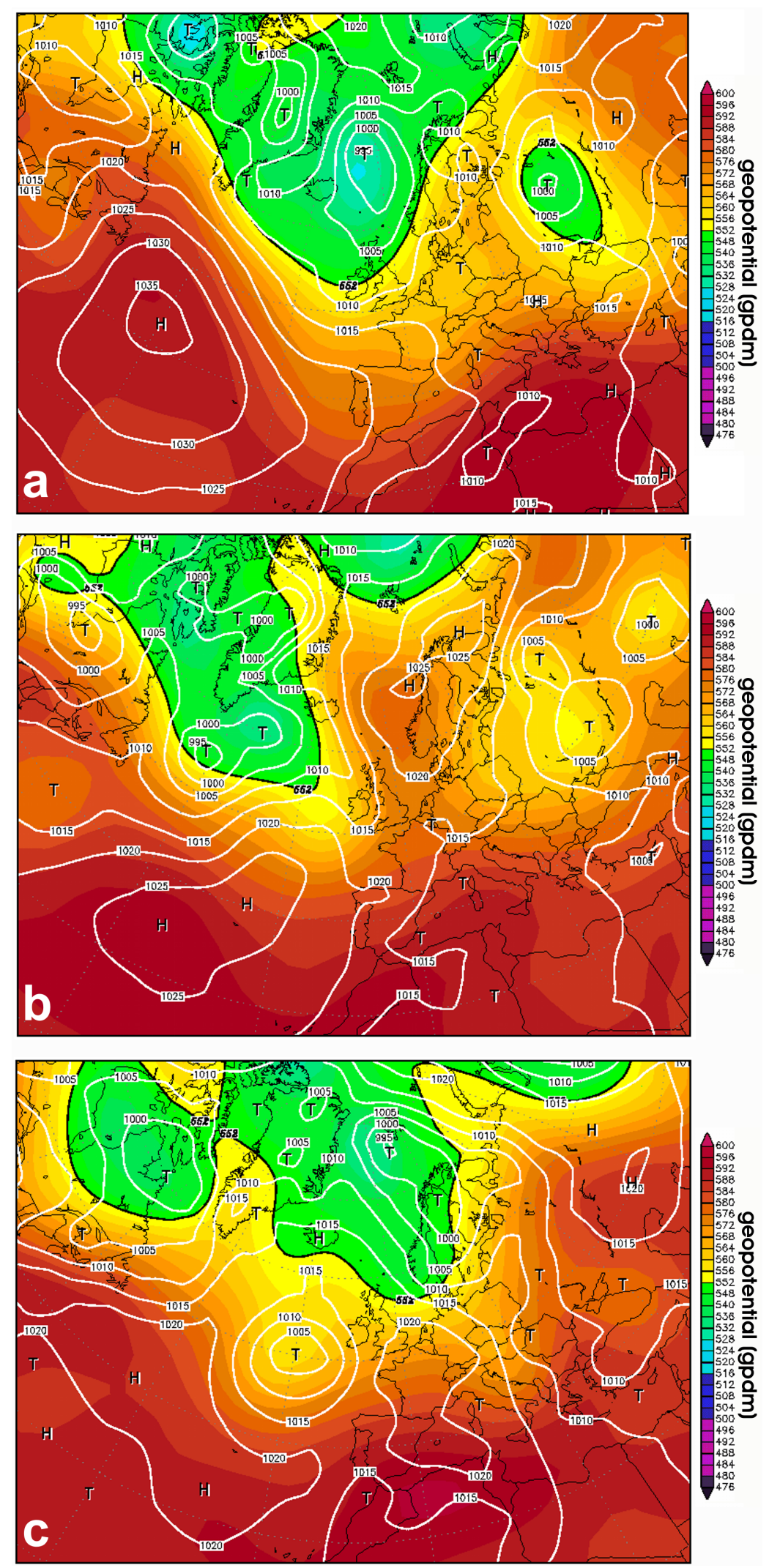

Fig. 3. Geopotential (gpdm) at 500-mb pressure level on (a) 21 June 1978, (b) 27 June 2003, and (c) 21 August 2004 (taken from http: //www.wetterzentrale.de). 


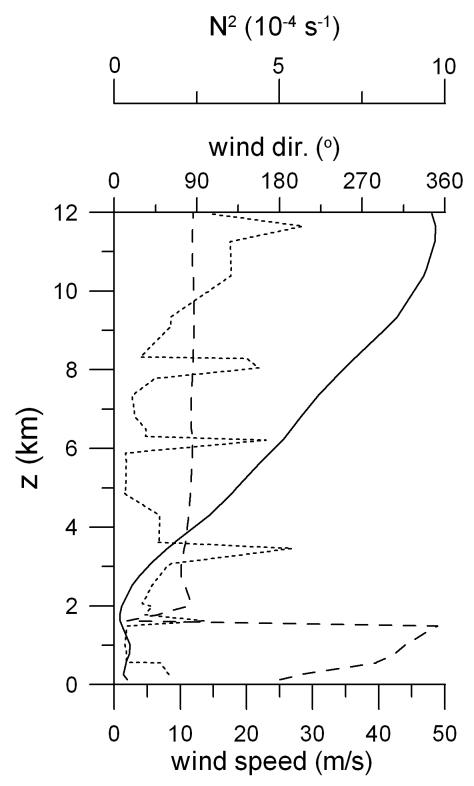

21 June 1978

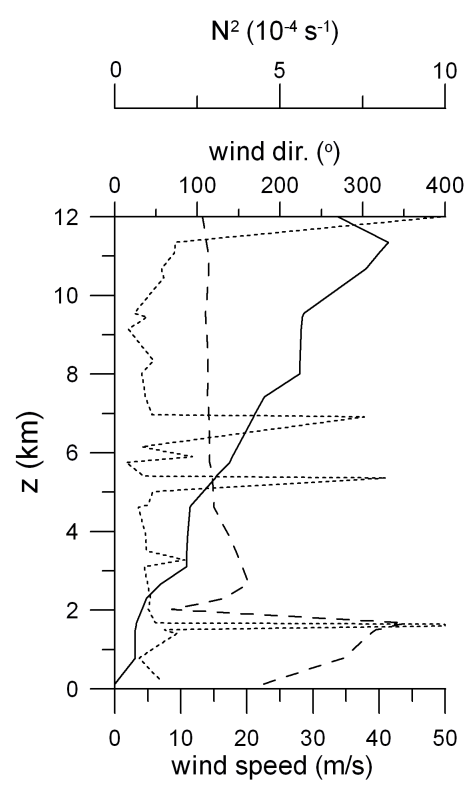

27 June 2003

Fig. 4. Vertical profiles of wind speed (full) and direction (dashed, oceanographic convention) and Brünt-Väisälä frequency ( $N^{2}$, dotted) obtained by radiosounding at the Zagreb station (300 km north from Split) on 21 June 1978 at 12:00 UTC (left) and 27 June 2003 at 12:00 UTC (right).

in the following way. The magnitude of the single incoming disturbance has been obtained from the air pressure data. The original air pressure series has been filtered with a high-pass filter having a cutoff period at $3.5 \mathrm{~h}$ (Z. Pasarić, unpublished), in order to subtract the influence of storm surges and the inverse barometric effect from the model results. Variable disturbance direction $\alpha$ in the numerical experiments has been computed from 6-h winds provided by the European Center for Medium Range Weather Forecast (ECMWF) at 500-mb level and has been linearly interpolated in time at each model time step, whereas in the experiments with constant direction it was assumed to have a value of $97^{\circ}$ (the disturbances are propagating along domain). A ECMWF grid point at $42.5^{\circ} \mathrm{N}$ and $15.0^{\circ} \mathrm{E}$ has been chosen for the acquisition of the disturbance direction $\alpha$, due to its location close to the western border of the model domain and therefore is representative for the wind at 500-mb level over the middle Adriatic coastal area. Each disturbance is assumed to travel with a constant speed and, in order to estimate its influence, three different constant values $(10,20$ and $30 \mathrm{~m} / \mathrm{s})$ are used in the numerical experiments. An instantaneous pressure disturbance field used by the model is obtained by space interpolation of successive travelling disturbances onto the model grid.

A two-day long (20 and 21 September 2000) time series of the measured air pressure at the PG station and the values reconstructed at the corresponding grid point (SP), together with the disturbance direction $\alpha$ are displayed in Fig. 2. The choice of the 500-mb level for the description of the disturbance direction $\alpha$, emerges from the analysis of three docu- mented meteotsunami episodes in the Adriatic Sea: 21 June 1978, 27 June 2003 and 21 August 2004. Figure 3 gives the geopotential (in gpdm) over Europe during these three events, and in all of these events the isolines over the middle Adriatic area are parallel to the documented directions of travelling air pressure disturbances, namely the disturbance propagated to $\mathrm{NE}\left(\alpha \sim 40^{\circ}\right)$ in the 1978 case (Orlić, 1980), whereas the geostrophic wind at the 500-mb level was directed approximately to ENE $\left(\alpha \sim 60^{\circ}\right)$ just west from the affected area (Fig. 3a). In fact, a similar wind direction is retained through the whole troposphere (Fig. 4), except in the first two kilometres. Such low-troposphere variability is probably related to the fact that the Zagreb radiosounding station is inland, $300 \mathrm{~km}$ north from Split (Fig. 1), and the flow was modified by the $1500-\mathrm{m}$ high mountain ridge. Both the 2003 and 2004 episodes were characterised with 500-mb winds directed towards ESE ( $\alpha \sim 100-110^{\circ}$, Figs. $3 \mathrm{~b}$ and c), exactly at the same direction ofthe disturbance propagation in the $2003\left(\alpha \sim 105^{\circ}\right.$, Vilibić et al., 2004) and $2004\left(\alpha \sim 95^{\circ}\right.$, Vilibić et al., 2005) cases. A similar vertical wind structure (a linear velocity increase with height and constant direction above $3 \mathrm{~km}$ or $700 \mathrm{hPa}$ ) is preserved in the 2003 case as in the 1978 case (Fig. 4); the only difference is the direction in middle and upper troposphere: $80^{\circ}$ in 1978 (winds directed ENE) and $115^{\circ}$ in 2003 (winds directed ESE). A difference of 10$20^{\circ}$ between the observed surface direction and the 500-mb stream may be the result of (i) an inaccurate computation of the surface direction from the analogue barographic charts, in particular for the 1978 case, and (ii) a spatial variability of 


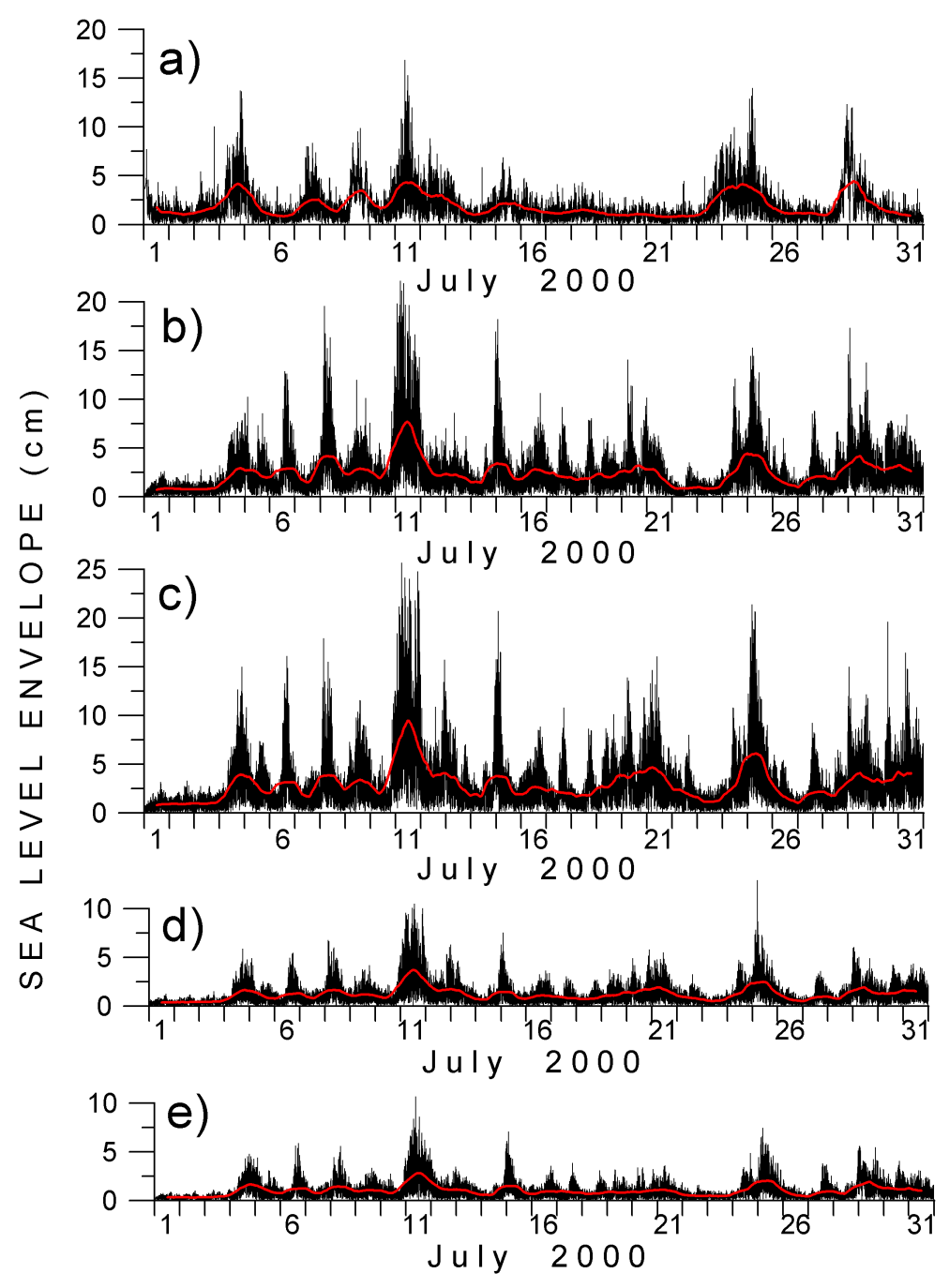

Fig. 5. Time series of sea level amplitudes (envelopes) in July 2000 computed from sea level series (a) measured at PG station and filtered by high-pass filter (cutoff at $3.5 \mathrm{~h}$ ), (b) modelled at SP grid point with variable $\alpha$ and $U=20 \mathrm{~m} / \mathrm{s}$, (c) modelled at SP grid point with constant $\alpha$ and $U=20 \mathrm{~m} / \mathrm{s}$, (d) modelled at SP grid point with variable $\alpha$ and $U=10 \mathrm{~m} / \mathrm{s}$, and (e) modelled at SP grid point with constant $\alpha$ and $U=10 \mathrm{~m} / \mathrm{s}$. Red curve stands for daily running average.

the 500-mb geopotential over the model domain, which cannot be recognized from the single point $\left(42.5^{\circ} \mathrm{N}, 15.0^{\circ} \mathrm{E}\right)$ of the 2.5 deg resolution ECMWF grid.

In order to quantify the influence of the variable disturbance direction versus a constant one (which must be applied when discarding the correlation between the 500-mb level processes and gravity wave direction), two groups of model runs were performed: (i) as described in the previous paragraph, with $\alpha$ equal to the $500-\mathrm{mb}$ wind direction at the $42.5^{\circ} \mathrm{N}, 15.0^{\circ} \mathrm{E}$ grid point, and (ii) with $\alpha=97^{\circ}$, which is the orientation of the model domain and the most of the channels in the investigated area. It is expected that the amount of the resonantly transferred energy to the sea will be significantly greater in the model runs with a constant disturbance direction. However, such an analysis will quantify an over- estimation, which may be the result of the impossibility to estimate the direction of the travelling gravity disturbance, which is hopefully bridged by analysing the ECMWF fields. As pressure measurements in a single point do not allow for an estimation of the disturbance speed, each of the model runs was repeated with a different disturbance speed $(10,20$ and $30 \mathrm{~m} / \mathrm{s}$ ), in order to quantify its effect on the model results.

\section{Results}

Let us verify the model results first on the available sea level data. Unfortunately, high-frequency data $(30 \mathrm{~s})$ were only available from the sea pressure sensor at $\mathrm{PG}$, while two other tide gauge stations operational in the model domain 

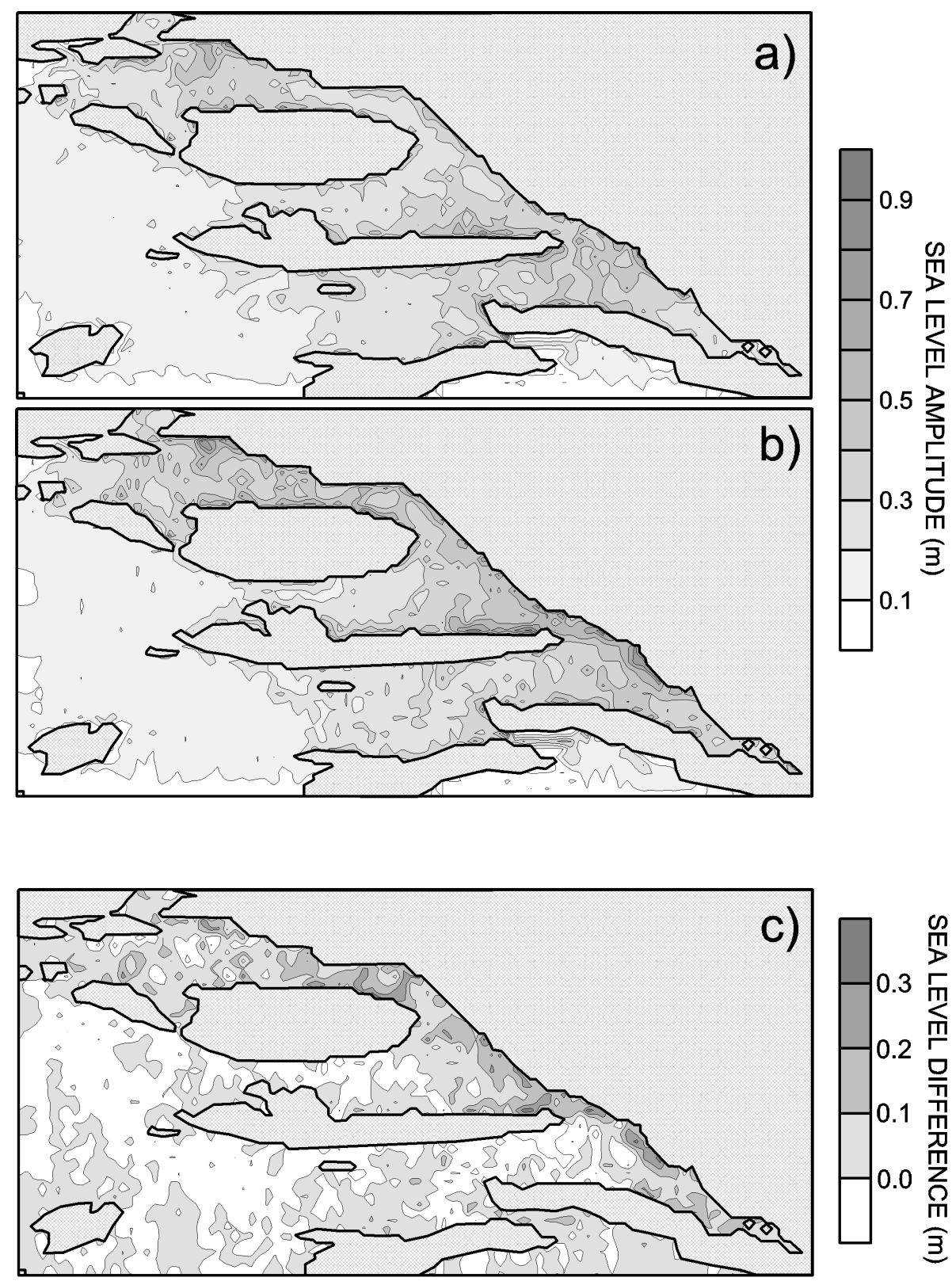

Fig. 6. Maximum sea level heights modelled with (a) variable $\alpha$ and $U=20 \mathrm{~m} / \mathrm{s}$ (model run 1 ), (b) constant $\alpha=97^{\circ}$ and $U=20 \mathrm{~m} / \mathrm{s}$ (model run 2), and (c) their difference.

were analogous at that time. The best data (just a few data missing) were collected during July 2000 and therefore were used for model verification. Figure 5 displays the envelope of high-frequency (cutoff period at $3.5 \mathrm{~h}$ ) sea level data at PG, together with modelled sea levels at SP grid point, both with variable and with a constant $\alpha$, and with disturbance speed of 10 and $20 \mathrm{~m} / \mathrm{s}$ (the results for $30 \mathrm{~m} / \mathrm{s}$ are similar to the ones of $10 \mathrm{~m} / \mathrm{s}$ and therefore are not shown). A couple of conclusions may be reached: (i) all model runs detect the events with large high-frequency oscillations, (ii) results of the model runs with variable disturbance direc- tion are slightly overestimated during some extreme events for $U=20 \mathrm{~m} / \mathrm{s}$ and largely underestimated for $U=10,30 \mathrm{~m} / \mathrm{s}$, while the results of the model runs, assuming a constant disturbance direction, are constantly overvalued for $U=20 \mathrm{~m} / \mathrm{s}$ and undervalued for $U=10,30 \mathrm{~m} / \mathrm{s}$, (iii) all runs sometimes reproduce "false events" (e.g. 15 July). The difference between runs with constant and variable disturbance directions resulted from the coastline orientation: the strongest energy transfer is appearing when the disturbance is travelling along the channels, which is fulfilled constantly in model runs with disturbance direction $\alpha=97^{\circ}$. This is also the reason for 


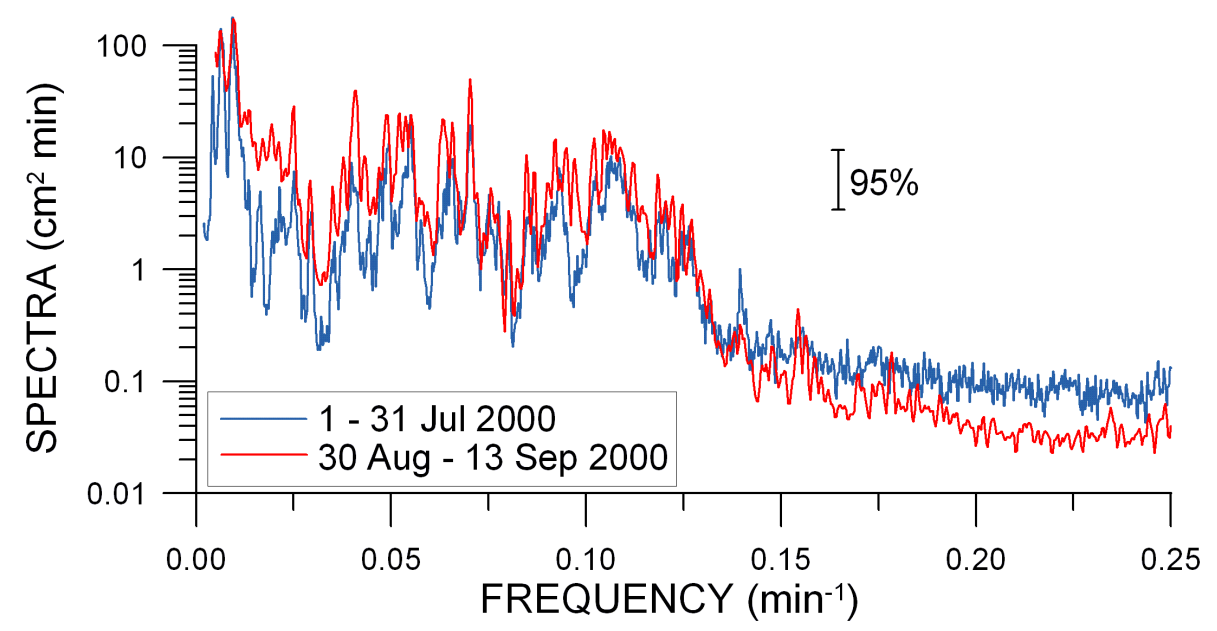

Fig. 7. Spectra of sea level data measured at PG station computed for two different intervals.

sea level overestimation in the model run with $\alpha=97^{\circ}$ and $U=20 \mathrm{~m} / \mathrm{s}$ and it is also supported by larger rms error (e.g. $2.15 \mathrm{~cm}$ ) than the one obtained for the corresponding model run using a variable direction $(1.85 \mathrm{~cm})$. The false events are probably the result of a rigid assumption that the speed of the atmospheric disturbances is constant over the whole period, but unfortunately, there is no possibility (and available data) to estimate the speed. This is probably (even surely) not a true, as the disturbances may change the speed in time over a region - they may also be variable in space (e.g. Vilibić et al., 2004), and they presumably transfer less energy to the sea than reconstructed $(U=20 \mathrm{~m} / \mathrm{s})$, since the real conditions are less favourable for the occurrence of a Proudman resonance. Yet, the total modelled energy amount assuming a variable disturbance direction and $U=20 \mathrm{~m} / \mathrm{s}$ in July 2000 , is almost the same as the energy of the measured high-frequency sea level oscillations. Conclusively, the model is capable of reproducing some characteristics of resonantly generated dynamics in the middle Adriatic coastal area, which makes this study useful in the description of the long-term characteristics of such oscillations.

Next, spatial analysis of some sea level elements will reveal the properties of resonantly generated sea level oscillations in the investigated area during a year. Since the best results were obtained using $U=20 \mathrm{~m} / \mathrm{s}$, in the following we will concentrate only on these two cases (run 1 and run 2). Modelled maximum sea levels (Fig. 6) during one year have the largest values near the shoreline, in particular in the area off Split and at some constrictions between the islands and the mainland (e.g. between eastern cape of Hvar and mainland, or between Pelješac and mainland). The reason for large sea levels modelled off Split is a shoal lying a few kilometres off the coast with a minimum depth of about $15 \mathrm{~m}$ (located $5 \mathrm{~km}$ east-southeast from PG station). The shoal is deepening towards the island of Brač to about $40-50 \mathrm{~m}$, while the depth is increasing to about $60 \mathrm{~m}$ west and east from the shoal. The position of the shoal coincides with the position of maximum sea levels in both model runs, with the values (model run 1, Fig. 6a) higher than $50 \mathrm{~cm}$ at the shallowest region. The shoal may be a reason for the appearance of trapped Poincaré waves, lying perpendicular to the channel axis along the shoal, coupled with other barotropic topographic waves and together having a variety of periods due to the complexity of the shoal and other topographical features in the area. These waves may also be seen in spectra computed for PG data (Fig. 7), encompassing the periods between 8 and $30 \mathrm{~min}$, already perceived in earlier work by Vilibić and Mihanović (2003), and recognized as a factor that worsens model results in the high-frequency band due to insufficient resolution of the bathymetry (e.g. Vilibić et al., 2004). Poincaré waves are presumably appearing at other constrictions, resulting in larger maximum sea levels, for example, on the northeastern coast of Hvar (up to 50-60 cm), between Pelješac and mainland (to about $40 \mathrm{~cm}$ ), etc.

The differences between model runs 1 and 2 are the largest close to the mainland shore, as it is aligned with the major domain axis and disturbance direction $\alpha$ in run 2, and amplifies the waves hitting the coast. The difference may be as large as $30 \mathrm{~cm}$ (Fig. 6c), which points to the importance of the proper estimation of the disturbance incoming direction. The importance of the direction is decreasing offshore, where the differences between the two runs are less than $10 \mathrm{~cm}$. However, the amount of total model energy is still larger for the second model run in most of the domain (Fig. 8) even far from the coast. The energy may be double or triple as large when considering no disturbance direction changes, particularly in the channels bordered by the mainland (Fig. 8c). In addition, the cumulative energy distribution outlines the importance of cross-shore trapped waves (Poincaré waves) and edge waves, which may be recognized from maximum cumulative energies appearing mostly along the island and mainland shorelines. The largest energies are modelled between east cape 

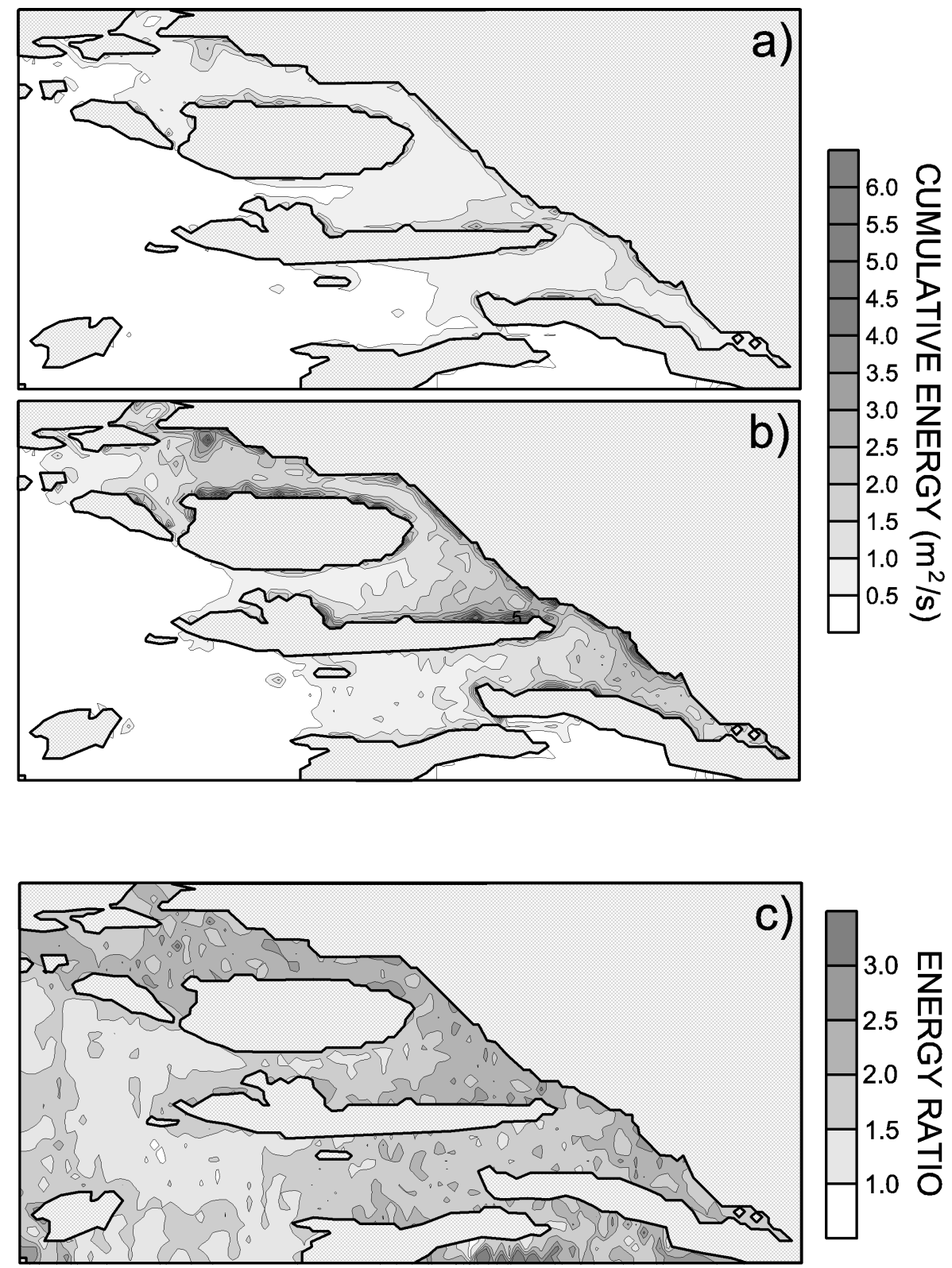

Fig. 8. Cumulative sea level energy modelled with (a) variable $\alpha$ and $U=20 \mathrm{~m} / \mathrm{s}$ (model run 1 ), (b) constant $\alpha=97^{\circ}$ and $U=20 \mathrm{~m} / \mathrm{s}$ (model run 2 ), and (c) their ratio.

of Hvar and the mainland (as maximum sea levels), between Pelješac and the mainland, and between the northern coast of Brač and Split area.

A two-day long time series with the most extreme episode in the run (Fig. 9) depicts the intensity of air pressure highfrequency oscillations consisting of a number of various disturbances with variable periods (from a few minutes to an hour). The most energetic event lasted for about $5 \mathrm{~h}$. Model results during this event reveal a sea level time series at the SP grid point varying within the maximum amplitude of $20 \mathrm{~cm}$. The disturbance direction $\alpha$ had a value of $60^{\circ}$ at that time, impacting the modelled sea levels which were
$40 \%$ larger, on average, when keeping constant $\alpha$ (model run 2). Similar average characteristics are also modelled for MS grid point where the disturbance arrived an hour later, and the maximum sea level in model run 2 is almost doubled $(35 \mathrm{~cm})$ versus the maximum sea level in model run 1 $(19 \mathrm{~cm})$. This difference is not negligible when studying the possible impacts of high-frequency phenomena to the coastal areas, including the evaluation of the risks to the infrastructure. Specific regions, such as Mali Ston Bay, may be rather sensitive to these scenarios, as a lot of shellfish farms are situated there, being prone to the impact of this phenomenon, as documented in June 2003 (Vilibić et al., 2004). 

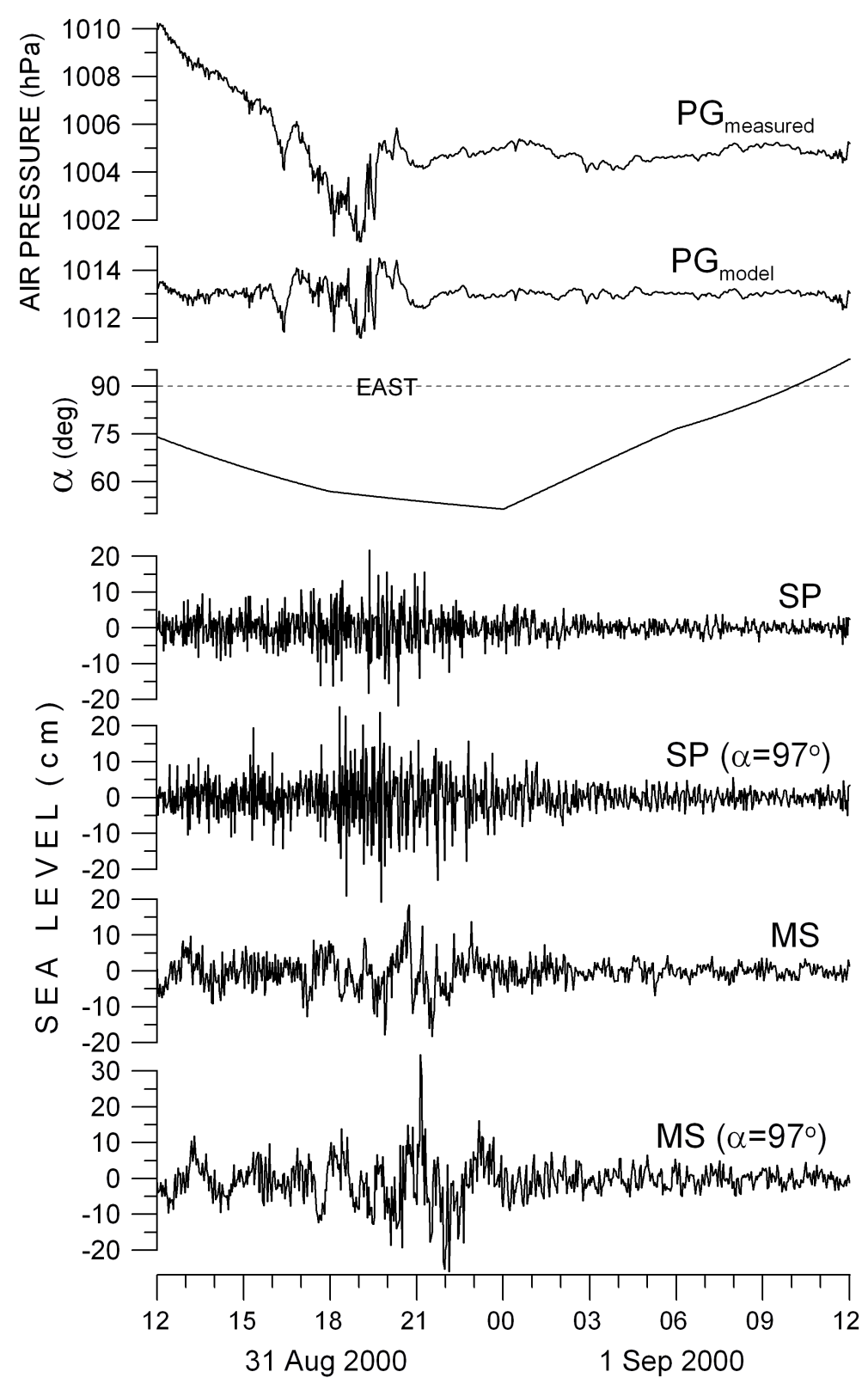

Fig. 9. Time series of measured air pressure $\left(\mathrm{PG}_{\mathrm{measured}}\right)$ and the corresponding series used by the model $\left(\mathrm{PG}_{\mathrm{model}}\right)$, disturbance direction $\alpha$, and of modelled sea levels with constant and variable $\alpha(U=20 \mathrm{~m} / \mathrm{s})$ at SP and MS grid points during 31 August and 1 September 2000 .

High-frequency oscillations are modelled to appear during the whole year (Fig. 10), which is in line with a recent observational study of the seiches in a middle Adriatic port (Vilibić and Mihanović, 2005). Yet it seems that the largest number of events appeared between January and April 2001 (days 180 to 300 ), although the most extreme events and floods in the past are documented in the summertime, namely in June and August (Orlić, 1980; Vilibić et al., 2004, 2005). However, the most extreme events are the result of a number of factors acting at the same time, including energy maximum positioned at the eigenperiods of an affected bay, which is beyond the scope of this study and needs a nesting approach to a particular bay (e.g. to the most vulnerable Stari Grad, Vela Luka and Mali Ston Bays). What may be seen in Fig. 10 is the quantity of the available energy in front of some bays/harbours, which is the largest in coastal areas (SP and MS) and lower on the outer islands (SG). Fortunately, Split Harbour has its natural mode at $6.5 \mathrm{~min}$ (Vilibić and Mihanović, 2002), which is not encompassed by the oscillations of modelled trapped waves $(8-30 \mathrm{~min})$ and therefore no floods occur in the harbour, although it is situated in the coastal area. An opposite situation is at Stari Grad, placed 


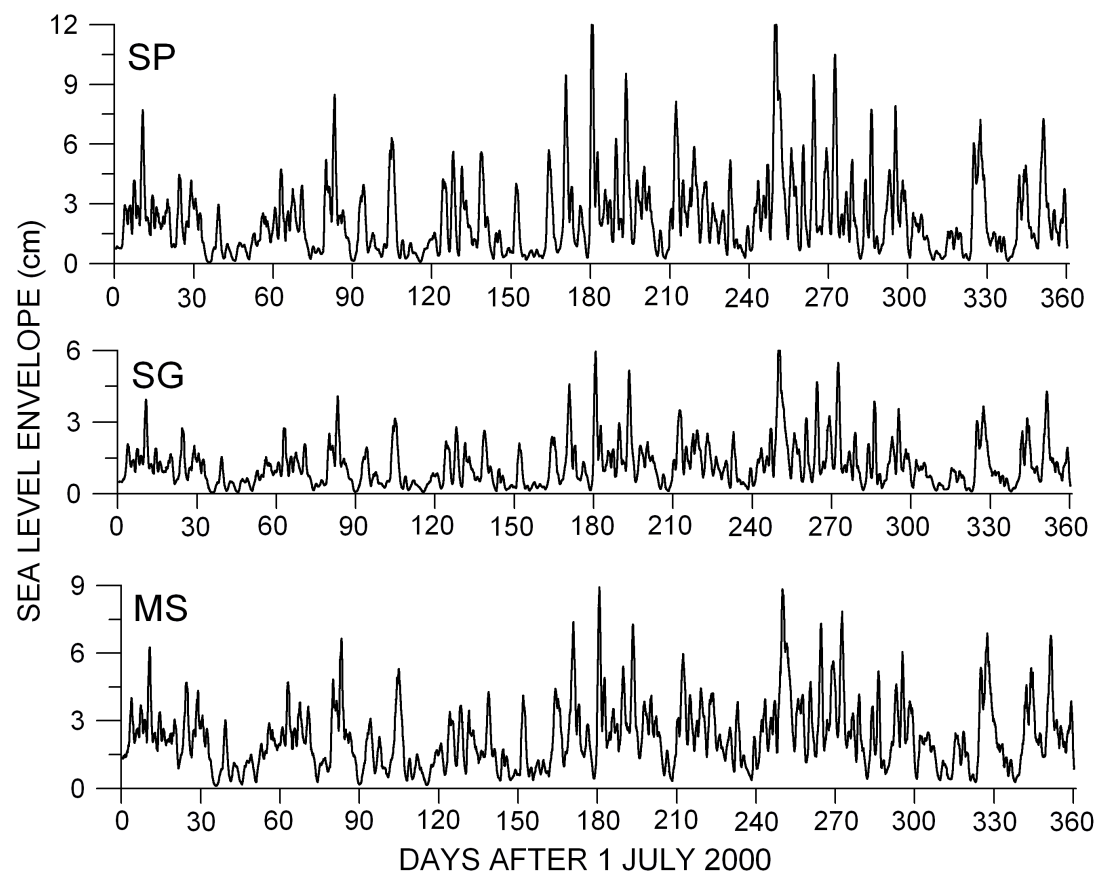

Fig. 10. Time series of modelled sea level amplitudes (envelopes) at SP, SG and MS grid points, smoothed by daily running average filter during the period between 1 July 2000 and 30 June 2001 (model run 1).

far from the coastland: eigenperiods of Stari Grad Bay are 11 and $6 \mathrm{~min}$, being close to the eigenperiods of the outer region, which makes the bay favourable for the appearance of large-amplitude oscillations (Vilibić, 2005).

Finally, some statistics may be computed from the results (Fig. 11). The most extreme events are modelled for March and April 2001, whereas the mean amplitude (envelope) is the largest in March. It may be seen that air pressure highfrequency oscillations were pronounced in March (large standard deviation), but they were also pronounced in November 2000 when quite low sea levels were modelled. The reason for such behaviour lies in the disturbance direction angle $\alpha$, with mean values of $45^{\circ}$ in November 2000 (disturbances travelled towards northeast) and $95^{\circ}$ in March 2001 (disturbances travelled towards east, along the domain axis and most of the channels). A maximum of modelled sea levels in December 2000 and April 2001 is also a result of favourable disturbance direction, although no strong disturbances appeared with a high frequency at that time (low air pressure range and standard deviation). Conclusively, the direction of an air pressure disturbance is quite an important factor for the generation of extreme sea levels in the middle Adriatic coastal waters.

\section{Discussion and conclusions}

The paper tries to highlight the influence of the spatial characteristics of the travelling atmospheric disturbances on their resonant coupling in the middle Adriatic coastal waters during one year (July 2000-July 2001). Coastal waters of the eastern middle Adriatic are chosen for such study, as they are known as a region where resonant coupling can occur forcefully. Although a good temporal description of the atmospheric phenomena and their impact to the sea may be reached by analysing 2-min air pressure series measured at Split, the lack of at least three such stations in the area disabled the possibility of obtaining their spatial characteristics (speed and propagation direction). Fortunately, the correlation between the direction of the high-frequency disturbance and the 500-mb geopotential data (and probably to some other levels, due to a nearly constant wind direction in middle and upper troposphere) during past documented extreme events inspired us to partly bridge this problem. Therefore, we suppose in our model runs (although this may not be a good assumption for all events) that a similar behaviour is reached for the greater part of the year, in order to compute some meteotsunami properties in the area. Yet the speed of a disturbance is still an unknown variable, assumed to be constant in this study and set up to a resonant value $(20 \mathrm{~m} / \mathrm{s})$ and surrounding ( 10 and $30 \mathrm{~m} / \mathrm{s}$ ) values, but the speed should be determined more accurately in the future.

Although the accurate knowledge of the spatial characteristics of the high-frequency atmospheric disturbances is still missing, on the basis of the numerical model results with small rms errors and a striking resemblance which corresponds to measured sea levels, the following conclusions may be drawn herein: 

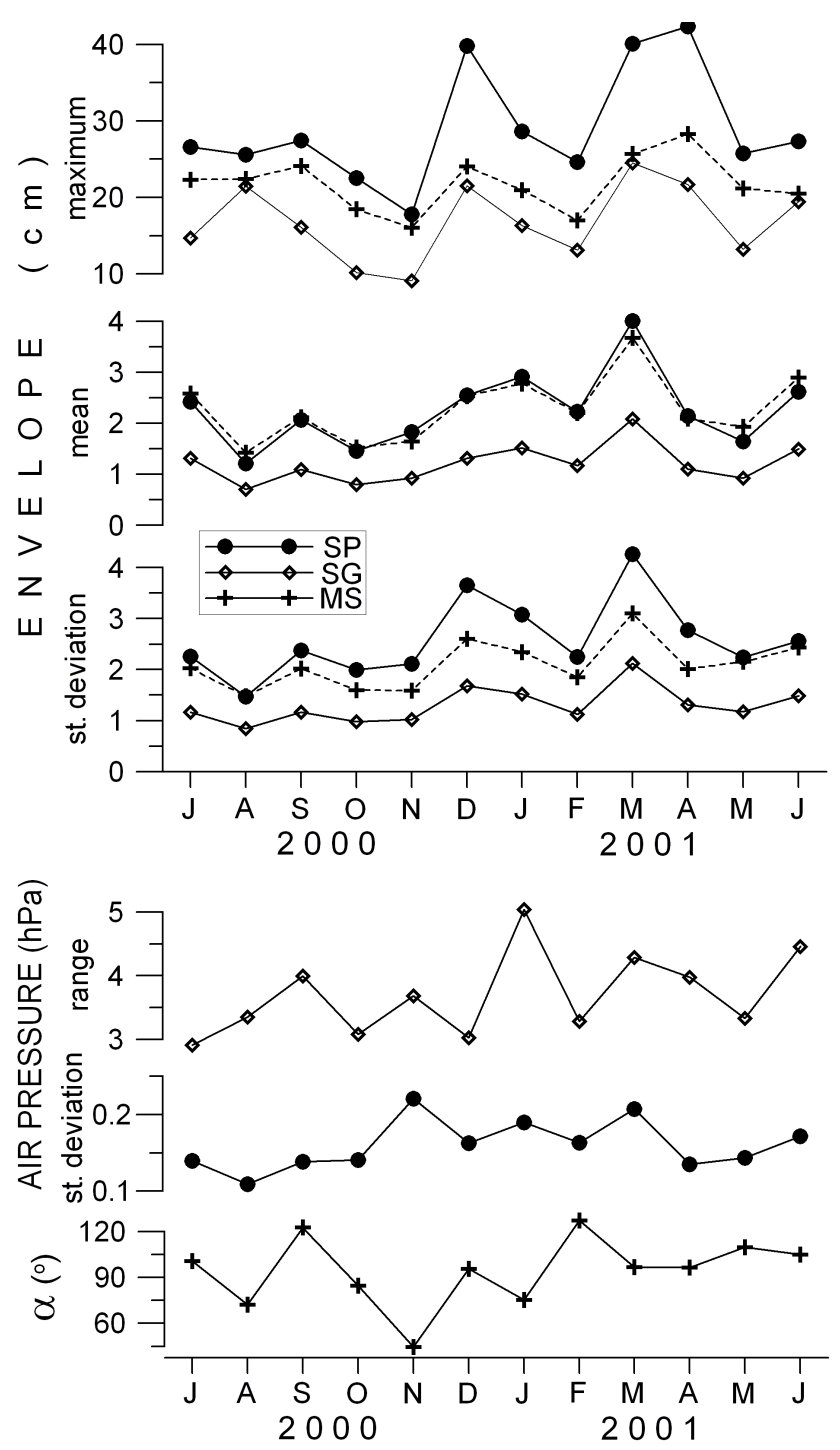

Fig. 11. Monthly series of maximum and mean amplitudes (envelopes) with standard deviations modelled at SP, SG and MS grid points, and the range and standard deviation of high-frequency air pressure series used by the model, together with mean disturbance direction angle $\alpha$ (model run 1).

- Large sea level oscillations, and also related currents, caused by a travelling atmospheric disturbance, may be of importance in low-tidal areas, such as the middle Adriatic, as they may reach $50 \mathrm{~cm}$ in some coastal areas.

- The strongest oscillations are modelled at the constraints (at the channel ends, for example between the east cape of Hvar and the mainland, between Pelješac and the mainland) and on the shoals (e.g. off Split), where a number of topographically trapped or progressive waves may be excited (e.g. Poincaré cross-shore waves, various eigenoscillations and edge waves).
- High-frequency oscillations in the sea may appear throughout a year, being driven by the travelling atmospheric disturbances. Nevertheless, some additional seasonal factors, which may influence the intensity of the phenomenon, should be examined in the future (e.g. impact of the vertical stratification on the strength of the high-frequency oscillations).

- The importance of the proper estimation of the disturbance propagation direction should be stressed, as it influences the amount of transferred energy to the sea even for 2-3 times, in particular along the shorelines, which are vulnerable to the flooding. It seems that the direction is even more important than the strength (energy) of the atmospheric disturbance, both for extreme events and for the mean estimates of the sea level oscillations. The same applies to the disturbance speed, which is not constant in time, as assumed in experiments, and also impacts the intensity of the ocean wave generation in the area.

Then next steps in these investigations should include the determination of a real atmospheric disturbance speed and a more accurate determination of the direction, maybe through the investigation of source mechanisms and the generation of such phenomena. However, the installation of two additional air pressure stations will enable the estimation of the disturbance speed, by separating its signal in the frequency domain and by examining its variation in space, which was already documented to occur over the investigated area (Vilibić et al., 2004; 2005). Such data will allow one to fully test the assumption given in the paper, and to validate the connection between large-scale processes in the atmosphere and highfrequency phenomena observable on the ground.

Acknowledgements. Sea level and air pressure data are kindly provided by Hydrographic Institute of the Republic of Croatia at Split. Wind directions at 500-mb level, obtained within ERA-40 project, are provided by ECMWF. Radiosounding data is granted by Meteorological and Hydrological Service of the Republic of Croatia. 2DD numerical model was developed by K. Black and was kindly provided from ASR Ltd, New Zealand, with assistance of Nenad Domijan. M. Pasarić and Z. Pasarić supplied us with the filtering software, I. Cerovečki developed the envelope computation software, while M. Orlić provided bathymetry file used in the model. S. Monserrat helped with the literature on atmospheric gravity waves. The comments given by E. Kulikov and the anonymous reviewer greatly improved the manuscript. The Ministry of Science, Education and Sport of the Republic of Croatia supported the research.

Topical Editor S. Gulev thanks E. Kulikov and another referee for their help in evaluating this paper.

\section{References}

Belušić, D., Grisogono, B., and Bencetić Klaić, Z.: A largeamplitude gravity wave over the Adriatic, Geophys. Res. Abstr., Vol. 8, 09666, 2006. 
Black, K. P.: The Numerical Hydrodynamic Model 3DD1 and Support Software, Occasional Report No. 19, Department of Earth Sciences, University of Waikato, New Zealand, 53, 1995.

Candela, J., Mazzola, S., Sammari, C., Limeburner, R., Lozano, C. J., Patti, B., and Bonnano, A.: The "Mad Sea" phenomenon in the Strait of Sicily, J. Phys. Oceanogr., 29, 2210-2231, 1999.

Defant, A.: Physical Oceanography, Vol. 2, Pergamon Press, New York, 592, 1961.

Drago, A.: Numerical modelling of coastal seiches in Malta, Workshop on Observing and Understanding Sea Level Variations, Book of Abstracts, St. Julians, Malta, 53, 2004.

Garcies, M., Gomis, D., and Monserrat, S.: Pressure-forced seiches of large amplitude in inlets of the Balearic Islands, 2, Observational study, J. Geophys. Res., 101(C3), 6453-6467, 1996.

Goring, D.: Rissaga (long-wave events) on New Zealand's eastern seaboard: a hazard for navigation, Proc. 17th Australasian Coastal and Ocean Engineering Conference, Adelaide, Australia, 137-141, 2005.

Herak, M., Orlić, M., and Kunovec-Varga, M.: Did the Makarska earthquake of 1962 generate a tsunami in the central Adriatic archipelago?, J. Geodyn., 31, 71-86, 2001.

Hibiya, T. and Kajiura, K.: Origin of the Abiki phenomenon (a kind of seiche) in Nagasaki Bay, Journal of the Oceanographical Society of Japan, 38, 172-182, 1982.

Lindzen, R. S. and Thung, K. K.: Banded convective activity and ducted gravity waves, Monthly Weather Review, 104, 16021617, 1976.

Monserrat, S. and Thorpe, A. J.: Gravity-wave observations using an array of microbarographs in the Balearic Islands, Quarterly Journal of the Royal Meteorological Society, 118, 259-282, 1992.

Monserrat, S. and Thorpe, A. J.: Use of ducting theory in an observed case of gravity waves, Journal of Atmospheric Sciences, 53, 1724-1736, 1996.

Monserrat, S., Ibbetson, A., and Thorpe, A. J.: Atmospheric gravity waves and the "Rissaga" phenomenon, Quarterly Journal of the Royal Meteorological Society, 117, 553-570, 1991a.

Monserrat, S., Ramis, C., and Thorpe, A. J.: Large amplitude pressure oscillations in the Western Mediterranean, Geophys. Res. Lett., 18, 183-186, 1991b.
Monserrat, S., Rabinovich, A. B., and Casas, B.: On the reconstruction of the transfer function for atmospherically generated seiches, Geophys. Res. Lett., 25(12), 2197-2200, 1998.

Orlić, M.: About a possible occurrence of the Proudman resonance in the Adriatic, Thalassia Jugoslavica, 16(1), 79-88, 1980.

Orlić, M., Dadić, V., Grbec, B., Leder, N., Marki, A., Matić, F., Mihanović, H., Beg Paklar, G., Pasarić, M., Pasarić, Z., and Vilibić, I.: Wintertime buoyancy forcing, changing seawater properties and two different circulation systems produced in the Adriatic, J. Geophys. Res., in press, 2006.

Papadopoulos, G. A.: On some exceptional seismic (?) sea-waves in the Greek archipelago, Science of Tsunami Hazards, 11, 2534, 1993.

Proudman, J.: The effects on the sea of changes in atmospheric pressure, Geophysical Supplement to the Monthly Notices of the Royal Astronomical Society, 2(4), 197-209, 1929.

Proudman, J.: Dynamical Oceanography, Methuen-John Wiley, London, 409, 1953.

Rabinovich, A. B.: Long Ocean Gravity Waves: Trapping, Resonance and Leaking, Gidrometeoizdat (in Russian), St. Petersburg, 325, 1993.

Rabinovich, A. B. and Monserrat, S.: Generation of meteorological tsunamis (large amplitude seiches) near the Balearic and Kuril Islands, Nat. Hazards, 18, 27-55, 1998.

Vilibić, I.: Numerical study of the Middle Adriatic coastal waters sensitivity to the various air pressure travelling disturbances, Ann. Geophys., 23, 3569-3578, 2005, http://www.ann-geophys.net/23/3569/2005/.

Vilibić, I. and Mihanović, H.: A study of seiches in the Split harbour (Adriatic Sea), Acta Adriatica, 43 (1), 59-68, 2002.

Vilibić, I. and Mihanović, H.: A study of resonant oscillations in the Split harbour (Adriatic Sea), Estuarine Coastal and Shelf Science, 56, 861-867, 2003.

Vilibić, I. and Mihanović, H.: Resonance in Ploče Harbor (Adriatic Sea), Acta Adriatica, 46(2), 125-136, 2005.

Vilibić, I., Domijan, N., and Čupić, S.: Wind versus air pressure seiche triggering in the Middle Adriatic coastal waters, Journal of Marine Systems, 57, 189-200, 2005.

Vilibić, I., Domijan, N., Orlić, M., Leder, N., and Pasarić, M.: Resonant coupling of a traveling air-pressure disturbance with the east Adriatic coastal waters. J. Geophys. Res., 109, C10001, doi:10.1029/2004JC002279, 2004. 